\title{
Review
}

\section{Signaling and transcriptional control of Fas ligand gene expression}

\author{
MM Kavurma $^{1,2}$ and LM Khachigian ${ }^{*, 1,2}$ \\ ${ }^{1}$ Centre for Thrombosis and Vascular Research, Department of Pathology, The \\ University of New South Wales, Sydney, NSW 2052, Australia \\ 2 Department of Haematology, The Prince of Wales Hospital, Sydney, Australia \\ * Corresponding author: LM Khachigian, Centre for Thrombosis and Vascular \\ Research, Department of Pathology, School of Medical Sciences, The \\ University of New South Wales, Sydney, NSW 2052, Australia; Tel: +61-2- \\ 9385 2537; Fax: +61-2-9385 1389; E-mail: L.Khachigian@unsw.edu.au
}

Received 19.6.02; revised 4.11.02; accepted 5.11.02 Edited by Dr Green

\begin{abstract}
Fas ligand (FasL), a member of the tumor necrosis factor family, initiates apoptosis by binding to its surface receptor Fas. As a consequence, there is sequential activation of caspases and the release of cytochrome $c$ from the mitochondria, with additional caspase activation followed by cellular degradation and death. Recent studies have shed important insight into the molecular mechanisms controlling FasL gene expression at the level of transcription. Nuclear factors such as nuclear factor in activated $T$ cells, nuclear factor-kappa B, specificity protein-1, early growth response factor, interferon regulatory factor, c-Myc and the forkhead transcriptional regulator, alone or cooperatively, activate FasL expression. These factors are often coexpressed with FasL in pathophysiologic settings including human atherosclerotic lesions. Here, we review these important advances in our understanding of the signaling and transcriptional mechanisms controlling FasL gene expression.

Cell Death and Differentiation (2003) 10, 36-44. doi:10.1038/ sj.cdd. 4401179
\end{abstract}

Keywords: Fas ligand; apoptosis; gene expression; transcription factor

Abbreviations: FasL, Fas ligand; SMC, smooth muscle cell; EMSA, electrophoretic mobility shift assay; DN, dominantnegative

\section{Introduction}

Fas ligand (FasL) was identified in 1993 as a type II transmembrane protein of $40 \mathrm{kDa}$ belonging to the tumor necrosis factor (TNF) family. FasL is one of the major effectors of CD8+ cytotoxic T lymphocytes and natural killer (NK) cells. ${ }^{1}$ The FasL system has been implicated in a number of pathogenic states. Soluble forms have been isolated from patients with large granular lymphocytic leukemia, NK cell lymphoma ${ }^{1}$ and a number of nonlymphoid tumor cells. ${ }^{2}$ Metalloproteinases are believed to be involved in the proteolytic cleavage of membrane-bound FasL, producing its soluble form, ${ }^{3}$ which exists as a trimer. ${ }^{4}$

The intracellular and extracellular domains of FasL are located in the $\mathrm{N}$ - and $\mathrm{C}$-terminal regions, respectively (see Figure 1 for FasL structure). FasL also consists of a single transmembrane domain and an oligomerization domain, which is required for self-assembly and appears to be well conserved in all TNF family ligands. ${ }^{5}$ The receptor-binding domain is located at the very end of the C-terminus, and deletion of at least three amino acids from this region is sufficient to interfere with interactions with its receptor, Fas. ${ }^{5}$ The proline-rich region in the cytoplasmic domain of FasL (amino acids 46-65) is responsible for sorting FasL to secretory lysosomes. ${ }^{6}$ A putative casein kinase I (CKI) motif (-SSASS-) has been identified; however, its role in FasL signaling remains to be determined. ${ }^{7}$ Additionally, three potential $\mathrm{N}$-glycosylation sites have also been acknowledged. ${ }^{5}$

Binding of FasL with Fas triggers the formation of the death-inducing signaling complex (DISC) by recruiting an adaptor molecule FADD (Fas-associating protein with death domain) to the cytoplasmic tail of Fas (C-terminal region). The $\mathrm{N}$-terminal region or death effector domains (DED) of FADD are critical for the recruitment of procaspase 8 . Immediately after recruitment, procaspase 8 is proteolytically processed to its active large and small subunits. At this point, the death-receptor initiated pathway can diverge in different cell types. Type I cells (mitochondria independent, Bcl-2 insensitive) induce apoptosis through the death-receptor initiated pathway to activate procaspase $3 .^{8}$ In other cell types (type II), caspase 8 is inadequate to activate procaspase 3 and cleaves Bid instead (a cytoplasmic protein) to activate the mitochondrial pathway with the release of cytochrome $c .^{8}$ In type II cells, Fas-induced apoptosis can also be blocked by prosurvival factors such as Bcl-2. Upon release, cytochrome $c$ is recruited to Apaf-1 (human homolog of Caenorhabditis elegans CED-4) followed by the formation of the apoptosome together with procaspase 9 . This complex then triggers the activation of caspase 3 and the cleavage of a variety of substrates including DNA repair enzymes, structural proteins and endonucleases. ${ }^{9}$ Although the idea of type I and type II cells has been widely accepted, Huang et al. ${ }^{10}$ recently reported opposing data. There is some controversy regarding the function of the survival factor $\mathrm{Bcl}-2$ on Fas-induced apoptosis. In this study, transgenic mice expressing Bcl-2 did not protect lymphocytes or hepatocytes from FasL/Fasinduced death. These results therefore imply identical FasL/ Fas signaling in both type I and type II cells, and challenge the 


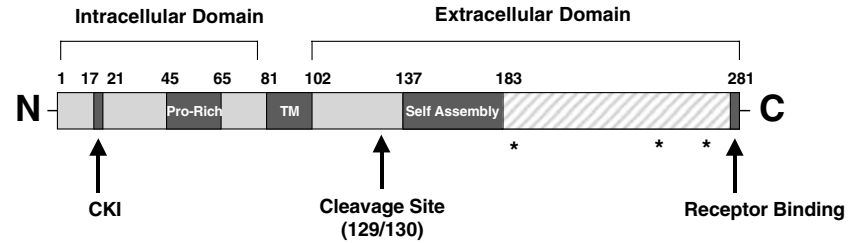

Figure 1 Structure of human FasL. FasL is synthesized as a 281-amino-acid protein. FasL contains a single transmembrane domain (TM), a proline-rich domain (Pro-Rich), a self-assembly domain and a putative casein kinase I (CKI) motif. Receptor binding occurs at the very end of the $\mathrm{COOH}$-terminus. Cleavage of FasL occurs at site $129 / 130$. * represents potential N-glycosylation sites (amino acids 184, 250 and 260, respectively). The hatched region denotes homology to other TNF family members

differential role of type I and type II cells in FasL-mediated death.

\section{Physiological and Pathological Roles of FasL-Mediated Apoptosis}

\section{Regulation of the immune response}

The FasL-Fas-mediated death pathway plays a major role in immune function, particularly in activation-induced cell death (AICD). AICD is an essential mechanism required to maintain cellular homeostasis in multicellular organisms. AICD functions to limit the excess proliferation of activated lymphocytes in the periphery after the elimination of antigen. It is also required for the elimination and inactivation of autoreactive thymocytes by negative selection within the thymus. In T cells and T-cell hybridomas, AICD arises through upregulation of FasL and Fas expression. T-cell receptor (TCR) triggering or stimulation by Staphylococcus enterotoxin B superantigen in $T$ cells induces FasL expression to promote apoptosis by AICD. ${ }^{11}$ FasL and Fas are both upregulated in T-cell hybridomas, ${ }^{12}$ and antagonists, including soluble Fas and antibodies directed to FasL, have been demonstrated to inhibit AICD. ${ }^{13}$

The role of FasL-Fas in AICD is further demonstrated by the development of lymphoproliferative disorders in mouse mutants. Mutants $\mathrm{g} / \mathrm{d} / \mathrm{g} / \mathrm{d}$ and $/ \mathrm{pr} / \mathrm{lp}$ rare defective in the genes encoding FasL and Fas, respectively. They are also defective in AICD. Mature T cells from gld and Ipr mice have defects in antigen-stimulated suicide, mediated by the FasL/Fasdependent pathway. ${ }^{14}$ In confirmation, activated T-cell hybridomas also do not undergo cell death in the presence of a Fas neutralizing antibody. B-cell homeostasis also appears to be regulated by FasL-Fas interactions. Observations in gld and Ipr mice have demonstrated an accumulation of $B$ cells and elevated levels of autoantibodies. ${ }^{15} \mathrm{FasL}$ is not expressed on the surface of resting or activated $B$ cells. ${ }^{16} B$ cells, however, can express its receptor, Fas. Deletion of $B$ cells by FasL on CD4+ T cells has been demonstrated, ${ }^{17}$ and a transgenic mouse line expressing Fas only in T cells was created using $I p r$ mice. ${ }^{18}$ These mice did not accumulate T cells but instead produced elevated levels of autoantibodies. These results suggest that FasL-expressing $T$ cells can kill Fas-expressing activated $B$ cells.
T-cell-mediated cytotoxicity is also an important factor in targeting and eliminating potentially harmful cells by apoptosis. Cytotoxic lymphocytes (CTL) comprise mainly CD8+ cytotoxic T cells and NK cells, and function to kill target cells (virus-infected and malignant cells) by two mechanisms. One pathway of CTL death occurs by calcium-dependent exocytosis of cytolytic granules from CTL. Cytotoxic granules contain proteins that are required for the destruction of the target cell including perforin and granzymes (serine proteases) (reviewed in Smyth et al. ${ }^{19}$ ). These proteins are secreted toward the target cell where they can penetrate the cytoplasm and nucleus of a cell, initiating cytosolic and nuclear apoptotic changes. The mechanism of granzyme death is not completely understood. Granzyme A and $B$ processes however, do initiate DNA fragmentation in the target cell but require perforin for activity. ${ }^{20,21}$ The most potent factor, granzyme $\mathrm{B}$, has been shown to activate cdc2 (a $\mathrm{G}_{2}$ cell cycle kinase), procaspase $3^{21}$ and the cytoplasmic protein Bid (involved in the mitochondrial apoptotic pathway). ${ }^{22}$ These actions are sufficient to induce cell death.

An additional mechanism of CTL cytotoxicity has been proposed based on the notion that effector $T$ cells from perforin knockout mice are still capable of inducing cell lysis and DNA fragmentation. ${ }^{23}$ This perforin/granzymeindependent pathway is thought to be because of FasLmediated death. FasL is expressed in some CTL, ${ }^{24}$ and CTL hybridomas that lyse Fas ${ }^{+}$but not Fas ${ }^{-}$cells suggest a role for FasL-Fas death in this process. ${ }^{25}$ Consistent with these observations and in a granule-independent manner, activated $\mathrm{T}$ cells from gld mice do not lyse $\mathrm{Fas}^{+}$target cells. $^{26}$

Recently, it was demonstrated that Fas engagement induced disseminated endothelial cell apoptosis in vivo. ${ }^{27}$ This study provides important immunopathological implications. Injection of anti-Fas monoclonal antibody (mAb) into mice produced an increase in endothelial cell apoptosis and vascular damage in a number of organs. Interestingly, when allogeneic lymphocytes from wild type, gld- or Ipr-deficient mice were transferred to SCID recipient mice, no lesions were formed from FasL-deficient gld cells. On the contrary, wildtype and Fas-deficient Ipr recipients displayed vascular lesions and endothelial cell apoptosis at levels similar to those observed with anti-Fas mAb. ${ }^{27}$ These results suggested that FasL-expressing activated $\mathrm{T}$ lymphocytes interact with Fas-expressing endothelial cells during nonallogeneic immune responses. ${ }^{27}$ Such responses may include infectious pathogens and tumors.

FasL has been thought to play an important role in sites of immune privilege (such as the eye and testis). ${ }^{28}$ Certain locations in the body are excluded from immune surveillance, as they cannot tolerate the damaging effects of inflammation. The eye and testis are immune privilege sites that have developed a protective mechanism against such damaging immune responses. Both the eye and testis constitutively express FasL. ${ }^{29}$ For some time, it was believed that FasL expression resulted in the death of invading Fas ${ }^{+}$cells within immune privilege sites. Evidence for such theories was provided by mutant mice models. Eyes of gld mice do not express functional FasL, and when infected with virus, the 
eyes were destroyed by inflammation. ${ }^{29}$ Corneal allografts from gld mice were also rejected. ${ }^{30}$ These results provided evidence that FasL expression in the eye was responsible for the successful corneal transplants observed in human patients.

Additional studies provided further confirmation on the role of FasL in immune privilege. Islets of Langerhans allograft rejection was prevented with myoblasts engineered to express FasL in mice. ${ }^{31}$ Moreover, testis grafts from mice expressing FasL survived when transplanted into allogeneic animals. ${ }^{32}$ On the contrary, grafts derived from mutant gld mice were rejected. ${ }^{32}$ Some groups also demonstrated that cancer cells became resistant to Fas-mediated apoptosis. ${ }^{33}$ The idea of cancer as a region of immune privilege was also recognized. There was evidence that tumor cells may have used FasL as a mechanism of immune evasion. Some tumor cells express FasL constitutively, ${ }^{34}$ and FasL from these cancer cells may have led to apoptosis of infiltrating lymphocytes. This had been demonstrated by a number of groups. $^{35,36}$

FasL has been thought to confer immune privilege, however recent data implies that this may not be the case. Restifo ${ }^{37}$ demonstrated that deficiency of FasL or Fas had no effect on the pathology of the eye, in an autoimmune uveitis model. ${ }^{37}$ Additional conflicting data were observed from a study conducted by Allison et al. ${ }^{38}$ In this study, fetal pancreas grafts from transgenic mice, expressing FasL on their islets $\beta$ cells, were transplanted under the kidney capsule of allogeneic mice. FasL expression failed to protect the grafts from rejection. Furthermore, granulocytic infiltration was observed in the pancreata of the transgenic mice. ${ }^{38}$ These results suggest that FasL expression may have a proinflammatory role and may not protect organ allografts from rejection. ${ }^{38}$ Over time several others have demonstrated FasL expression to cause rejection of transplantations with extreme inflammation. ${ }^{39}$ Similar observations were also seen in experimental tumor systems. ${ }^{39}$

The alleged role of FasL in immune privilege may have been because of false-positive data, based on controversial monoclonal antibodies used in experimental conditions. Additional controversy regarding the use of Fas antibodies has been raised. ${ }^{10}$ Huang et al. ${ }^{10}$ questioned the validity of Fas antibodies and how accurately these antibodies reflected the physiological mechanisms of Fas-induced apoptosis. Most data on sensitivity to Fas have been derived from studies using anti-Fas mAbs. To resolve these significant issues, a number of experiments were performed to elucidate the effects of Fas inducers on different cell lines. Huang et al. ${ }^{10}$ demonstrated that only membrane-bound and multimerized (aggregated) FasL induced apoptosis reliably. This was also observed by Janin et al. ${ }^{27}$ The capacity of soluble FasL to trigger apoptosis depended on the degree of soluble FasL multimerization. ${ }^{27}$ It was also observed that antibodies to Fas did not dependably mimic FasL. ${ }^{10}$ They proposed that anti-Fas mAb alone did not sufficiently support receptor crosslinking, particularly in type II cells. Type II cells became highly sensitive to crosslinked anti-Fas mAb. ${ }^{10}$ Additionally, under certain conditions, mAbs to Fas could antagonize Fas-induced cell death. Therefore, studies using anti-Fas mAbs may not provide reliable data, since they may not accurately imitate the physiological functions of FasL. Thus, the role of FasL in immune privilege, tumor counterattack and inflammation needs to be considered with caution.

\section{FasL-induced death in vascular disease}

Apoptosis is not limited to an immune response. Programmed cell death has also been observed during vascular development and interestingly within the arterial wall in atherosclerosis, hypertension and restenosis. ${ }^{40,41}$ Regression of the thickened arterial wall early in these pathologies by apoptosis could reduce the neointima. ${ }^{42}$ Both FasL and Fas are expressed in the normal and diseased vessel walls. ${ }^{43}$ Sata et al. $^{44}$ demonstrated FasL-induced cell death by an adenovirus encoding FasL (adeno-FasL). Adeno-FasL induced apoptosis in $\mathrm{Fas}^{+}$vascular smooth muscle cells (SMCs) in a paracrine manner and inhibited neointima formation in rats. Local delivery of adeno-FasL to proliferating vascular SMCs after balloon injury in rats also induced apoptosis. ${ }^{44}$ In addition, a flow-restricted ligation model of injury, performed by Sata and Walsh ${ }^{45}$ in FasLdefective gldmice, displayed greater neointima and enhanced leukocyte infiltration compared to wild type. ${ }^{45}$ These results suggest that the FasL-Fas pathway can function to restrict inflammation and intimal hyperplasia during vascular remodeling.

It has also been proposed that since vascular SMCs express Fas and inflammatory cells express FasL, FasLFas-mediated apoptotic cell death may contribute to atherosclerotic plaque instability. ${ }^{43}$ SMCs are the principal cellular components of atherosclerotic plaques capable of producing the collagen required to maintain tensile strength. It has been proposed that vascular SMC death within vulnerable regions of atherosclerotic plaques may lead to destabilization and plaque rupture. ${ }^{46}$ Several lines of evidence suggest a positive role for the FasL/Fas death pathway in atherosclerotic plaques. Firstly, expression of Fas has been found in both inflammatory and vascular SMCs. ${ }^{43} \mathrm{Fas}^{+}$vascular SMCs are located prominently within the intima of plaques ${ }^{43}$ and Fas has also been demonstrated to colocalize with TUNEL-positive vascular SMCs in regions consisting of CD3+ T-cells and CD68+ macrophages. ${ }^{47}$ Geng et al. ${ }^{48}$ also demonstrated positive staining for FasL in 34 out of 34 carotid plaques and the majority of this staining was localized with intimal vascular SMCs. Recently, it was also concluded that human macrophages induce apoptosis of vascular SMCs derived from carotid plaque. ${ }^{49}$ Macrophageinduced SMC apoptosis was inhibited by a neutralizing antibody to FasL or Fas-Fc fusion protein, suggesting that this process may promote plaque rupture. ${ }^{49}$ In a more clinical setting, the role of FasL-mediated death in myocardial infarction was examined by Shimizu et al. ${ }^{50}$ In this study, plasma of acute myocardial infarction (AMI) or stable/ unstable angina pectoris (AP) patients were measured for soluble FasL (sFasL). Shimizu et al. ${ }^{50}$ demonstrated that patients with AMI and unstable AP have elevated levels of sFasL, indicating a role for the FasL-Fas system in vascular disease. 


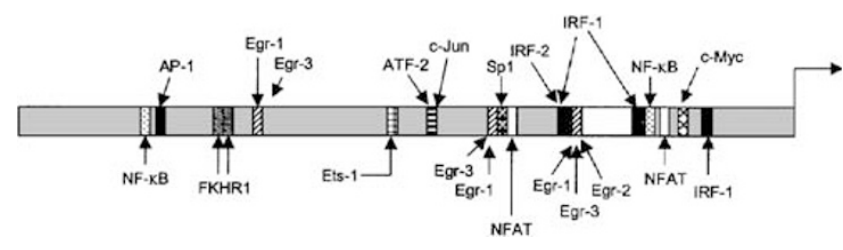

Figure 2 Transcriptional regulation of Fas ligand. Nuclear factors activating transcription of the FasL gene are illustrated in this schematic. Boxes represent cis-regulatory elements located in the proximal FasL promoter known to regulate FasL gene expression with indicated transcription factors. References are provided in the text.

\section{Transcriptional Regulation of Fas Ligand}

FasL gene expression is controlled by distinct protein-DNA interactions at the FasL promoter. Transcriptional control of FasL gene expression has previously been the focus of a review. ${ }^{51}$ Transcriptional regulation of FasL since then, however, has significantly developed and a number of different factors have been identified to regulate FasL gene expression. Examples of these include transcription factors such as specificity protein-1 (Sp1), Ets-1 (homolog of viral ets), interferon regulatory factor-1 (IFN-1) and inducible cAmp early repressor (ICER) (Figure 2; see Table 1 for coordinates). Here we will discuss in some detail the transcriptional signaling machinery involved in FasL gene expression, including mechanisms of stress and cytokine-induced expression. Elucidation of precise mechanisms underlying FasL gene expression may provide useful molecular insights on the disease states associated with FasL.

Nuclear factor in activated T cells (NFAT), a member of the enhancer binding protein family, is critical for the expression of many cytokine genes ${ }^{52}$ and is involved in the regulation of TCR-mediated FasL expression. ${ }^{53}$ Two NFAT sites have been identified through DNase I footprinting studies from nuclear extracts of activated $T$ cells. Both sites are shown to be of importance, although mutational studies have demonstrated the distal NFAT binding site to have a more significant role. ${ }^{53}$ Human T-cell leukemia virus type I (HTLV-1)-infected T cells constitutively express FasL. HTLV1 induces transcription of FasL through the viral transactivator, tax. ${ }^{54}$ The previously identified consensus NFAT binding site ${ }^{53}$ is required for tax activation, and the NFAT motif is essential for activation of the FasL promoter by TCR signals.

Nuclear factor-kappa B (NF- $\kappa$ B) is a ubiquitous transcription factor involved in the expression of many genes including cytokines, growth factors and cell adhesion molecules. ${ }^{55}$ The inducible form of NF- $\kappa$ B is a heterodimer of NF- $\kappa$ B1 and Rel A. Inactive NF- $\kappa$ B is found in the cytoplasm in a complex with an inhibitory protein $\mathrm{I}-\kappa \mathrm{B}$. Once activated, NF- $\kappa \mathrm{B}$ is released from $\mathrm{I}-\kappa \mathrm{B}$, translocates to the nucleus and activates target genes. ${ }^{56}$ Two NF- $\kappa$ B sites have been identified in the mouse promoter of FasL (FasL- $\kappa$ B1 and FasL- $\kappa$ B2). ${ }^{57}$ Both sites were found to bind NF- $\kappa \mathrm{B}$; however, only the FasL- $\kappa \mathrm{B} 1$ site was able to activate gene expression. ${ }^{57} \mathrm{NF}-\kappa \mathrm{B}$-dependent upregulation of FasL has also been demonstrated in apoptosis of etoposide- and teniposide-treated Jurkat Tcells. ${ }^{58}$ Moreover, the FasL promoter was responsive to DNA damage and coexpression with p65 (Rel A) or Fos/Jun. Mutations in NF- $\kappa$ B and activator protein-1 (AP-1) binding sites eliminated these responses, indicating a crucial role for both NF- $\kappa$ B and AP-1 in FasL expression and apoptosis. ${ }^{58}$ Like NFAT, NF- $\kappa$ B also plays a role in T-cell activationinduced FasL expression. ${ }^{59}$ Inhibition of NF- $\kappa$ B activity in Tcell hybridomas reduced FasL expression and apoptosis upon

Table 1 Transcriptional regulators of FasL gene expression

\begin{tabular}{|c|c|c|c|c|}
\hline Transcription factor & Strand & Response element & Coordinates & Reference \\
\hline NFAT & + ve & $5^{\prime}$-GGAAA-3' & $-137 /-133$ & 53 \\
\hline NFAT & $+\mathrm{ve}$ & $5^{\prime}-\mathrm{GGAAA}^{\prime} 3^{\prime}$ & $-270 /-272$ & 53,54 \\
\hline $\mathrm{NF}-\kappa \mathrm{B}$ & - ve & 5'-GGGGACTTTCT-3' & $-1086 /-1076$ & 58 \\
\hline $\mathrm{NF}-\kappa \mathrm{B}^{\mathrm{a}}$ & $+v e$ & 5'-AGGTGTTTCCC-3' & $-138 /-128$ & 57 \\
\hline $\mathrm{NF}-\kappa \mathrm{B}^{\mathrm{a}}$ & $+\mathrm{ve}$ & 5'-TGGTCTTTTCCC-3' & $-440 /-429$ & 57 \\
\hline$A P-1$ & $+\mathrm{ve}$ & $5^{\prime}$-TTAGTCAG-3' & $-1050 /-1043$ & 58 \\
\hline Sp1 & + ve & $5^{\prime}-\mathrm{GGGCGG-3^{ \prime }}$ & $-280 /-275$ & 60,62 \\
\hline Ets-1 & $+\mathrm{ve}$ & $5^{\prime}-\mathrm{GGAA}-3^{\prime}$ & $-366 /-363$ & 61 \\
\hline Egr-1, Egr-3, Egr-2 & + ve & 5'-GTGGGTGT-3' & $-215 /-208$ & 63 \\
\hline Egr-1, Egr-3 & + ve & 5'-GTGGGCGG-3' & $-282 /-275$ & 65,66 \\
\hline Egr-1, Egr-3 & + ve & 5'-GTGGGTGT-3' & $-784 /-777$ & 65 \\
\hline IRF-1, IRF-2 & +ve & $5^{\prime}-\mathrm{AAGTGA}-3^{\prime}$ & $-221 /-216$ & 69 \\
\hline IRF-1 & $+\mathrm{ve}$ & 5'-GAGAAGAAGTAAAACCGTTTG-3' & $-49 /-29$ & 70 \\
\hline IRF-1 & + ve & $5^{\prime}$-AGAGAAAGAGAAAGACAGAGG-3' & $-174 /-154$ & 70 \\
\hline c-Myc & - ve & 3'-ATTCTCT-5' & $-127 /-121$ & 76 \\
\hline FKHRL1 & $+\mathrm{ve}$ & 5'-TAAATAAATA-3' & $-897 /-888$ & 78 \\
\hline FKHRL1 & $+\mathrm{ve}$ & 5'-TAAATAAATA-3' & $-885 /-876$ & 78 \\
\hline FKHRL1 & +ve & 5'-TAAGTAAATA-3' & $-889 /-880$ & 78 \\
\hline ATF-2/c-jun & + ve & $5^{\prime}$-TTGGGTAGCACAGCGA-3' & $-335 /-320$ & 81 \\
\hline
\end{tabular}

Nuclear factors involved in the transcriptional regulation of FasL are listed. Coordinates and sequences corresponding to transcription factor cis-elements (relative to transcriptional start site) in human FasL proximal promoter are noted

aMouse FasL promoter sequence 
TCR stimulation. Coexpression of p65 (Rel A) on the FasL promoter induced FasL activity. In contrast, coexpression of I$\kappa \mathrm{B}$ dramatically reduced inducible FasL promoter activity. ${ }^{59}$ Unlike inducible FasL expression by DNA-damaging agents, AP-1 was not required for activation-induced FasL gene expression. ${ }^{59}$

A broadly expressed zinc-finger transcription factor, Sp1, is involved in the transcriptional regulation of many genes and can influence gene expression by promoter interactions through architectural support and by chemical modification. Sp1 has also been identified to be important in the regulation of FasL gene expression and apoptosis. We recently demonstrated that inducible FasL gene expression in SMC involves the zinc-finger transcription factor Sp1, which in turn is regulated by the atypical protein kinase C-zeta $(\mathrm{PKC} \zeta) .{ }^{60}$ Sp1 activated the FasL promoter via a distinct recognition element, and inducible FasL promoter activation was abrogated by expression of the dominant-negative (DN) mutant form of Sp1. Inducible FasL transcription and apoptosis were also blocked using DN-PKC $\zeta$. We also showed that Ets-1 positively activates FasL gene expression in SMC. ${ }^{61}$ Furthermore, Ets-1 activation of the FasL promoter involved a distinct recognition element and cooperative interactions with Sp1. ${ }^{61}$ Using immunohistochemical staining, we found that Ets-1, Sp1, PKC $\zeta$ and FasL were expressed in smooth muscleactin $^{+}$TUNEL $^{+}$SMCs of human carotid atherosclerotic plaques. ${ }^{60}$ The Sp1 element in the FasL promoter overlaps with an NFAT binding motif. This region (5'-GGGCGGAAA-3') is critical for FasL promoter activity in IL-2 treated T cells. ${ }^{62}$ Mutation of the Sp1 and/or NFAT sites reduced FasL promoter activity. ${ }^{62}$ In contrast, mutation at the early growth response factor (Egr) site had no effect on FasL transcription. $^{62}$

Mittelstadt and Ashwell ${ }^{63}$ identified a sequence on the FasL promoter that binds Egr transcription factor family members termed the FasL regulatory element (FLRE). Electrophoretic mobility shift assays (EMSA) identified two activation-induced nuclear protein complexes, Egr-1 and Egr3 to bind this region. ${ }^{63}$ The transcription factor Egr-1 is implicated in growth, differentiation and apoptosis. ${ }^{64}$ The function of Egr-3 on the other hand remains unknown. Transient overexpression of Egr-3 increased FasL promoter activity in a cyclosporin A-insensitive manner. In contrast Egr-1 had no effect. ${ }^{63}$ Li-Weber et al. ${ }^{65}$, through DNase I footprinting, identified an additional two Egr binding sites on the FasL promoter. Both Egr-1 and Egr-3 were found to form nucleoprotein complexes at these identified sites. ${ }^{65}$ Moreover, NFAT was also a component of the induciblebinding complexes formed. In the same study, Egr-1, Egr-3 and NFAT displayed cooperative and synergistic activation of the FasL promoter mediated by the three Egr/NFAT regulatory elements. ${ }^{65}$ Egr-2 also showed a positive regulatory role in FasL transcription. ${ }^{66}$ Mittelstadt and Ashwell ${ }^{66}$ demonstrated that both Egr-3 and Egr-2 induced FasL-promoterdependent reporter activity in T-cell hybridomas and HeLa cells. Egr-3 and Egr-2 also upregulated endogenous FasL mRNA. ${ }^{66}$

Regulation of FasL by NFAT via Egr factors has been established by Rengarajan et al. ${ }^{67}$ Through Northern, EMSA and promoter-dependent studies using cells of NFAT-defi- cient mice, Egr2 and Egr3 were shown to be regulated by NFAT proteins. ${ }^{67}$ Primary lymph node cells from mice lacking NFATp, NFAT4, Egr2 and Egr3 were also used to assess direct transactivation of the FasL promoter by Egr2 and Egr3, under the regulatory control of NFAT. Interestingly, expression of NFAT together with a minimal FasL promoter construct (containing the FLRE) demonstrated significant induction of the reporter vector. The fact that coexpression of Egr3 together with the minimal FasL reporter vector bearing a mutation in FLRE demonstrated near extinction of FasLpromoter upregulation further supports the notion that NFAT controls the regulation of Egr2 and/or Egr3 to regulate FasL transcriptional activity. ${ }^{67}$ In addition to these studies, Yang et al. ${ }^{68}$ recently established the synergistic activation of the FasL promoter by coexpression of Egr2 or Egr3 and the human immunodeficiency virus (HIV) transactivator, Tat. Mutations in FLRE no longer supported this superinduced activation. ${ }^{68}$ This study also established that Egr2 and Egr3 physically interacted with Tat. Interaction with Egr3 was still supported by an amino-acid substitution in Tat that blocked its transactivation activity; however, this mutation failed to enhance Egr-dependent regulation of the FasL promoter. $^{68}$

TCR-inducible FasL expression is under the direct influence of the interferon transcription factor family. Deletion and mutagenesis studies identified a $12 \mathrm{bp}$ sequence in the FasL promoter containing a putative interferon regulatory factor (IRF) binding site. ${ }^{69}$ EMSA demonstrated the formation of DNA-binding complexes to contain IRF-1 and IRF-2. Overexpression of either IRF-1 or IRF-2 resulted in FasL promoter activation, although the activation observed was more significant by IRF-1 overexpression. ${ }^{69}$ IRF-1 and IRF-2 overexpression also lead to an increase in endogenous FasL mRNA levels in heterologous nonlymphoid cells. Kirchhoff et al. ${ }^{70}$ identified two positive IRF-dependent domains in the FasL promoter. EMSA demonstrated IRF-1 binding to both sites, where IRF-1 overexpression induced FasL promoter activity. Interestingly, Kirchhoff et al. ${ }^{70}$ demonstrated that both sites are important in TCR/CD3mediated FasL induction, and that viral IRF of human herpesvirus 8 (HHV8) abolish IRF-1-mediated, and abrogate TCR/CD3-mediated FasL induction. Thus, inhibition of FasLdependent T-cell function may contribute to the immune escape of HHV8. ${ }^{70}$

The transcription factor c-Myc dimerizes with Max to form an active transcriptional complex involved in cell cycle progression, neoplasia and cell death. Little is known regarding mechanisms of c-Myc-mediated apoptosis. c-Myc has been shown to promote apoptosis in fibroblasts. ${ }^{71}$ Studies have demonstrated the involvement of c-Myc in AICD of T cells through the use of antisense oligonucleotides targeting ${\mathrm{C}-M y c^{72}}^{72}$ and dominant-negative mutant forms of c-Myc or Max. ${ }^{73}$ Hueber et al. ${ }^{74}$ revealed that c-Myc-induced apoptosis requires functional $F a s L$ and $F a s$, and these findings were confirmed by Brunner et al. ${ }^{75}$ Brunner et al. ${ }^{75}$ demonstrated that T-cell activation-induced expression of FasL is regulated by c-Myc. c-Myc has been illustrated to interact directly with the FasL promoter. A 'noncanonical' binding site has been identified ( $3^{\prime}$-ATTCTCT-5') for c-Myc-Max heterodimers, ${ }^{76}$ and $\mathrm{c}-$ Myc activation of the FasL promoter was abolished 
upon mutation of this binding element. ${ }^{76}$ Transforming growth factor-beta (TGF $\beta$ ) also downregulates FasL transcriptional activity via c-Myc. TGF $\beta 1$ has been shown to block c-Mycinduced FasL mRNA and subsequent activation of apoptosis in T cells. ${ }^{77}$ This provides a possible mechanism for AICD downregulation that may allow for clonal expansion during an immune response. ${ }^{77}$

Survival factors such as nerve growth factor (NGF) and insulin-like growth factor 1 (IGF1) trigger a cascade of events leading to the activation of the phosphatidylinositol 3-kinase (PI3K)-Akt pathway. Akt directly inhibits members of the apoptotic machinery including BAD and caspase 9. The forkhead transcriptional regulator-1 (FKHRL1) is a substrate of Akt phosphorylation. ${ }^{78}$ The release of survival factors leads to the phosphorylation of FKHRL1, rendering it inactive as a transcription factor. Dephosphorylation of FKHRL1 contributes to FasL upregulation and apoptosis. ${ }^{78}$ Brunet et al. ${ }^{78}$ identified three putative overlapping response elements to FKHRL1 in the FasL promoter. Only two of these response elements were found to bind FKHRL1. ${ }^{78}$ Recently, Suhara et al. ${ }^{79}$ demonstrated that serum deprivation and treatment of vascular SMC with wortmannin (PI3K inhibitor) ablated Akt signaling and led to the upregulation of FasL. Akt suppression also induced c-Jun N-terminal kinase (JNK) and DN mutants of c-Jun inhibited FasL promoter activity. ${ }^{79}$ Induction of FasL by FKHRL1 was dependent on C-Jun activation. ${ }^{79}$ Suhara et al. ${ }^{79}$ established a positive feedback loop mechanism where FasL participates in and promotes apoptosis under conditions of cellular stress.

\section{Stress-Induced FasL Transcription}

Environmental stress stimuli such as cytotoxic stress and DNA-damaging agents can trigger responses that control cellular processes including repair, cell cycle arrest and programmed cell death. The induction of FasL gene expression in T lymphocytes in response to environmental stress has been shown to be dependent on JNK activation. ${ }^{80} \mathrm{C}$-Jun translocates to the nucleus following phosphorylation by JNK. Within the nucleus it binds to c-Fos forming a complex, AP-1. The MEKK1 (JNK kinase kinase)-regulated response element was identified by Faris et al. ${ }^{80}$ on the FasL promoter. Mutation of this response element greatly reduced MEKK1-mediated FasL promoter activation. EMSA demonstrated specific binding by an AP-1 heterodimer consisting of activating transcription factor 2 (ATF-2) and c-Jun. Transfection of cJun and ATF-2 mutants (lacking JNK phosphorylation sites) decreased transcriptional activation of FasL. Faris et al. ${ }^{80}$ thus demonstrated that MEKK1, and transcription factors regulated by the JNK pathway play a role in committing lymphocytes to undergo apoptosis via FasL transcription in a stress-responsive manner.

JNK to FasL signaling pathways also play important roles in the induction of neuronal cell death in response to various stresses. $^{81}$ Treatment with truncated MEKK1 (MEKK1A) or NGF withdrawal leads to an increase in FasL transcriptional activity. The p38 inhibitor SB202190 blocked FasL induction and C-Jun phosphorylation. ${ }^{81}$ SB20358 activation induced FasL expression, and overexpression of mitogen-activated protein kinase (MAPK) kinase 3b (activator of p38 MAPK) led to an increase in FasL promoter activity and an increase in transcript in T cells. In addition, Kasibhatla et al. ${ }^{58}$ demonstrated that etoposide, teniposide and ultraviolet-induced Tcell apoptosis occurs through the activation of FasL. They also demonstrated that these stimuli activated the JNK pathway. These responses were abrogated by mutations in AP-1 and $\mathrm{NF}-\kappa \mathrm{B}$, indicating a role for $\mathrm{AP}-1$ and $\mathrm{NF}-\kappa \mathrm{B}$ in stress-induced apoptosis. $^{58}$

\section{Cytokine-Induced FasL Gene Expression}

The role of IL-2 in apoptosis is not completely established. In fact, IL-2 rescues activated T cells from apoptosis by inducing antiapoptotic genes including Bcl-2. ${ }^{82}$ Other studies, however, suggest that IL-2 primes T cells to TCR-mediated programmed cell death. ${ }^{83}$ These findings are confirmed by the observation that IL-2-deficient mice exhibit an increase in lymphocyte production, uncontrolled T-cell activation and autoimmunity. ${ }^{84}$ More recently, Haux et al. ${ }^{85}$ revealed that NK cells exposed to IL-2 over 3 days became apoptotic and released soluble FasL, indicating the involvement of FasL/Fas in the downregulation of IL-2-activated human NK cells. ${ }^{85} \mathrm{IL}-2$ also increased transcription and surface expression of FasL, ${ }^{86}$ and Xiao et al. ${ }^{62}$ further demonstrated this by functional FasL promoter studies. It was found that IL-2induced FasL-promoter-dependent expression was mediated via the Sp1 and NFAT binding motifs. ${ }^{62}$

Ayroldi et al. ${ }^{87}$ also demonstrated that transcription of FasL/ Fas is controlled by IL-2 production and that CD2 stimulation rescued $\mathrm{T}$-cell hybridomas from AICD through a reduction in IL-2. Ayroldi et al. ${ }^{87}$ also showed negative regulation of the FasL/Fas system with the involvement of interleukin-6 (IL-6). IL-6 was found to inhibit anti-CD3-induced apoptosis in a Tcell hybridoma line, thus demonstrating a protective effect. IL6 did not inhibit IL-2 production, suggesting IL-2-independent mechanisms of FasL/Fas expression. ${ }^{87} \mathrm{~A}$ significant decrease was also observed in the anti-CD3-induced expression of FasL and IL- 6 rescued resting $T$ cells from apoptosis, by activating $\mathrm{Bcl}-2$ expression. ${ }^{88}$

$\operatorname{TGF} \beta$, a cytokine that regulates cell growth, adhesion and differentiation, ${ }^{89}$ has contradictory actions and its role in apoptosis is not clear. There are a number of conflicting studies that demonstrate $\operatorname{TGF} \beta$ to have a negative ${ }^{90}$ and a positive role in apoptosis. ${ }^{77}$ Recently, Genestier et al. ${ }^{77}$ demonstrated negative regulation of apoptosis by TGF $\beta 1$ through the transcriptional regulation of FasL. They showed that TGF $\beta 1$ inhibited c-Myc expression in T-cell hybridomas, and a chimeric molecule consisting of c-Myc and the estrogen receptor's steroid binding domain blocked FasL and AICD stimulated by TGF $\beta 1 .{ }^{77}$ Schlapbach et al. ${ }^{91}$ showed that TGF $\beta$ induced Flice-inhibitory protein (c-FLIP) in resting and activated microglia, and they demonstrated that the presence of FLIP strongly interfered with FasL-induced activation of caspase 8 and caspase 3, preventing apoptosis. ${ }^{91}$ On the contrary, TGF $\beta$ is required for programmed cell death in the developing mouse limb, ${ }^{92}$ where levels of apoptosis were reduced in the interdigital spaces of the developing limbs of Tgf-beta2 ${ }^{-1-}$ Tgf-beta3 $^{-1-}$ double 
knockouts. Arsura et al. ${ }^{93}$ also demonstrated a positive role in TGF $\beta$-induced apoptosis. They showed that TGF $\beta$-induced programmed cell death is preceded by a reduction in C-Myc expression, which is associated with a decrease in $\mathrm{NF}-\kappa \mathrm{B}$ expression. $^{93}$

\section{Negative Regulation of FasL Transcription}

Repression of FasL expression has been demonstrated by a number of factors including retinoic acid, nitric oxide, vitamin $\mathrm{D}_{3}$ and the transcriptional repressor ICER. Treatment of T-cell hybridomas with retinoic acid and glucocorticoids inhibits FasL upregulation and subsequent apoptosis. ${ }^{94,95}$ The ability of retinoic acid to inhibit AICD was enhanced by overexpression of the retinoid $X$ receptor $(R X R) .{ }^{96}$ The inhibition of apoptosis was blocked by the dominant-negative mutant form of RXR. ${ }^{96}$ Yang et al. ${ }^{96}$ demonstrated efficient inhibition of FasL upregulation and T-cell apoptosis by retinoids binding to their respective receptors.

Recently, Lee et al. ${ }^{95}$ illustrated the repression of FasL by retinoic acid, mediated via an NFAT binding element. EMSA determined a reduction in the ability of NFAT to bind DNA following retinoic acid treatment and revealed that retinoic acid blocked the translocation of NFAT from the cytosol to the nucleus. ${ }^{95}$ In a similar manner, nitric oxide also inhibited FasL expression and apoptosis by interfering with the ability of AP-1 to induce FasL expression. ${ }^{97}$ Moreover, vitamin $D_{3}$ inhibited activation-induced apoptosis and FasL gene expression. This repression was shown to be mediated by a noncanonical cMyc binding element. ${ }^{98}$ In addition, the transcriptional repressor ICER has also been identified as a downregulator of FasL expression in T lymphocytes. Bodor et al. ${ }^{99}$ recently demonstrated the transcriptional repression of activated human FasL promoter by ICER, and the involvement of the proximal NFAT binding element. The study illustrated the formation of a ternary complex between ICER and the DNAbinding domain of NFAT via the proximal NFAT element. ${ }^{99}$ Increased expression of ICER also correlated with a decrease in FasL expression in both $\mathrm{T}$ and NK cells. ${ }^{99}$ In support of these observations, Bodor et al. ${ }^{99}$ illustrated that a proximal NFAT binding site participates in the downregulation of the FasL promoter by ICER. Thus, FasL is likely to be controlled by complex interactions via positive and negative regulatory factors.

\section{Conclusion}

In recent years, a distinct pattern of FasL gene expression has emerged, involving transcription factor interactions with distinct promoter elements, protein-protein combinatorial interactions and phosphorylation. These molecular events integrate signals from outside the cell to changes in FasL gene expression, altering cell phenotype and triggering cell death. Future work should provide a more complete picture of the signaling, transcriptional and post-transcriptional regulation of this mediator of cell death.

\section{Acknowledgments}

LMK is a Principal Research Fellow of the National Health and Medical Research Council of Australia.

\section{References}

1. Nagata S (1999) Fas ligand-induced apoptosis. Annu. Rev. Genet. 33: 29-55

2. O'Connell J, Bennett MW, O'Sullivan GC, Collins JK and Shanahan F (1999) The Fas counterattack: cancer as a site of immune privilege. Immunol. Today 20: $46-52$

3. Tanaka M, Suda T, Haze K, Nakamura N, Sato K, Kimura F, Motoyoshi K, Mizuki M, Tagawa S, Ohga S, Hatake K, Drummond AH and Nagata S (1996) Fas ligand in human serum. Nat. Med. 2: 317-322

4. Tanaka M, Suda T, Takahashi T and Nagata S (1995) Expression of the functional soluble form of human fas ligand in activated lymphocytes. EMBO J. 14: $1129-1135$

5. Orlinick JR, Elkon KB and Chao MV (1997) Separate domains of the human Fas Ligand dictate self-association and receptor binding. J. Biol. Chem. 272: 32221-32229

6. Blott EJ, Bossi G, Clark R, Zvelebil M and Griffiths GM (2001) Fas Ligand is targeted to secretory lysosomes via a proline-rich domain in the cytoplasmic tail. J. Cell. Sci. 114: 2405-2416

7. Wenzel J, Sanzenbacher R, Ghadimi M, Lewitzky M, Zhau Q, Kaplan DR, Kabelitz D, Feller SM and Janssen $O$ (2001) Multiple interactions of the cytosolic polypropoline region of the CD95 ligand: hints for the reverse signal transduction capacity of a death factor. FEBS Lett. 509: 255-262

8. Budihardjo I, Oliver H, Lutter M, Luo X and Wang X (1999) Biochemical pathways of caspase activation during apoptosis. Annu. Rev. Cell Dev. Biol. 15: 269-290

9. Cohen GM (1997) Caspases: the executioners of apoptosis. Biochem. J. 326 : 1-16

10. Huang DCS, Hahne M, Schroter M, Frei K, Fontana A, Villunger A, Newton K, Tschopp J and Strasser A (1999) Activation of Fas by FasL induces apoptosis by a mechanism that cannot be blocked by Bcl-2 or Bcl- $\mathrm{X}_{\mathrm{L}}$. Proc. Natl. Acad. Sci. USA 96: 14871-14876

11. Dhein J, Walczak H, Baumler C, Debatin KM and Krammer PH (1995) Autocrine T-cell suicide mediated by APO-1/(Fas/CD95). Nature 373: 438-441

12. Brunner T, Mogil RJ, LaFace D, Yoo NJ, Mahboubi A, Echeverri F, Martin SJ, Force WR, Lynch DH, Ware CF and Green DR (1995) Cell-autonomous Fas (CD95)/Fas-ligand interaction mediates activation-induced apoptosis in T-cell hybridomas. Nature 373: 441-444

13. Ju ST, Panka DJ, Cui H, Ettinger R, el-Khatib M, Sherr DH, Stanger BZ and Marshak-Rothstein A (1995) Fas(CD95) FasL interactions required for programmed cell death after T-cell activation. Nature 373: 444-448

14. Russell JH, Rush B, Weaver C and Wang R (1993) Mature T cells of autoimmune Ipr//pr mice have a defect in antigen-stimulated suicide. Proc. Natl. Acad. Sci. USA 90: 4409-4413

15. Giese T and Davidson WF (1994) Chronic treatment of C3H-Ipr/lpr and C3Hgld/gld mice with anti-CD8 monoclonal antibody prevents the accumulation of double negative T cells but not autoantibody production. J. Immunol. 152: 2000-2010

16. Watanabe D, Suda T and Nagata S (1995) Expression of Fas in B cells of the mouse germinal center and Fas-dependent killing of activated B cells. Int. Immunol. 7: 1949-1956

17. Rathmell JC, Cooke MP, Ho WY, Grein J, Townsend SE, Davis MM and Goodnow CC (1995) CD95 (Fas)-dependent elimination of self-reactive B cells upon interaction with CD4+ T cells. Nature 376: 181-184

18. Fukuyama H, Adachi M, Suematsu S, Miwa K, Suda T, Yoshida N and Nagata $S$ (2002) Requirement of Fas expression in B cells for tolerance induction. Eur. J. Immunol. 32: 223-230

19. Smyth MJ, Kelly JM, Sutton VR, Davis JE, Browne KA, Sayers TJ and Trapani JA (2001) Unlocking the secrets of cytotoxic granule proteins. J. Leuk. Biol. 70: $18-29$ 
20. Shi L, Mai S, Israels S, Browne K, Trapani JA and Greenberg AH (1997) Granzyme B (GraB) autonomously crosses the cell membrane and perforin initiates apoptosis and GraB nuclear localization. J. Exp. Med. 185: $855-866$

21. Shi L, Chen G, He D, Bosc DG, Litchfield DW and Greenberg $A H$ (1996) Granzyme B induces apoptosis and cyclin A-associated cyclindependent kinase activity in all stages of the cell cycle. J. Immunol. 157: 2381-2385

22. Barry M, Heibein JA, Pinkoski MJ, Lee SF, Moyer RW, Green DR and Bleackley RC (2000) Granzyme B short-circuits the need for caspase 8 activity during granule-mediated cytotoxic. T-lymphocyte killing by directly cleaving Bid. Mol. Cell. Biol. 20: 3781-3794

23. Kagi D, Ledermann B, Burki K, Hengartner H and Zinkernagel RM (1994) CD8+ $\mathrm{T}$ cell-mediated protection against an intracellular bacterium by perforindependent cytotoxicity. Eur. J. Immunol. 24: 3068-3072

24. Suda T, Takahashi T, Golstein P and Nagata S (1993) Molecular cloning and expression of the Fas ligand, a novel member of the tumor necrosis factor family. Cell 75: 1169-1178

25. Rouvier E, Luciani MF and Golstein P (1993) Fas involvement in $\mathrm{Ca}(2+)$ independent T cell-mediated cytotoxicity. J. Exp. Med. 177: 195-200

26. Ramsdell F, Seaman MS, Miller RE, Tough TW, Alderson MR and Lynch DH (1994) gld/gld mice are unable to express a functional ligand for Fas. Eur. J. Immunol. 24: 928-933

27. Janin A, Deschaumes C, Daneshpouy M, Estaquier J, Micic-Polianski J, Rajagopalan-Levasseur P, Akarid K, Mounier N, Gluckman E, Socie G and Ameisen JC (2002) CD95 engagement induces disseminated endothelial cell apoptosis in vivo: immunopathologic implications. Blood 99: 29402947

28. Nagata S (1997) Apoptosis by death factor. Cell 88: 355-365

29. Griffith TS, Brunner T, Fletcher SM, Green DR and Ferguson TA (1995) Fas ligand-induced apoptosis as a mechanism of immune privilege. Science 270: 1189-1192

30. Stuart PM, Griffith TS, Usui N, Pepose J, Yu X and Ferguson TA (1997) CD95 ligand (FasL)-induced apoptosis is necessary for corneal allograft survival. J. Clin. Invest. 99: 396-402

31. Lau HT, Yu M, Fontana A and Stoeckert CJJ (1996) Prevention of islet allograft rejection with engineered myoblasts expressing FasL in mice. Science 273 109-112

32. Bellgrau D, Gold D, Selawry H, Moore J, Franzusoff A and Duke RC (1995) A role for CD95 ligand in preventing graft rejection. Nature 377: 630-632

33. O'Connell J, Bennett MW, O'Sullivan GC, Collins JK and Shanahan F (1999) Resistance to Fas (APO-1/CD95)-mediated apoptosis and expression of Fas Ligand in esophageal cancer: the Fas counterattack. Dis Esophagus 12: 83-89

34. Chappell DB and Restifo NP (1998) T cell-tumor cell: a fatal interaction? Cancer Immunol. Immunother. 47: 65-71

35. Hahne M, Rimoldi D, Schroter M, Romero P, Schreier M, French LE, Schneider P, Bornand T, Fontana A, Lienard D, Cerottini J and Tschopp J (1996) Melanoma cell expression of Fas(Apo-1/CD95) ligand: implications for tumor immune escape. Science 274: 1363-1366

36. Bennett MW, O'Connell J, O'Sullivan GC, Brady C, Roche D, Collins JK and Shanahan $F(1998)$ The Fas counterattack in vivo: apoptotic depletion of tumorinfiltrating lymphocytes associated with Fas ligand expression by human esophageal carcinoma. J. Immunol. 160: 5669-5675

37. Restifo NP (2001) Countering the 'counterattack' hypothesis. Nat. Med. 7: 259

38. Allison J, Georgiou HM, Strasser A and Vaux DL (1997) Transgenic expression of CD95 ligand on islet $\beta$ cells induces a granulocytic infiltration but does not confer immune privilege upon islet allografts. Proc. Natl. Acad. Sci. USA 94 3943-3947

39. Restifo NP (2000) Not so Fas: re-evaluating the mechanisms of immune privilege and tumor escape. Nat. Med. 6: 493-495

40. Isner JM, Kearney M, Bortman S and Passeri J (1995) Apoptosis in human atherosclerosis and restenosis. Circulation 91: 2703-2711

41. Kockx M and De Meyer G (1996) Apoptosis in human atherosclerosis and restenosis. Circulation 93: 394-395

42. Pollman MJ, Hall JL, Mann MJ, Zhang L and Gibbons GH (1998) Inhibition of neointimal cell bc1-x expression induces apoptosis and regression of vascular disease. Nat. Med. 4: 222-227
43. Geng YJ, Henderson LE, Levesque EB, Muszynski M and Libby P (1997) Fas is expressed in human atherosclerotic intima and promotes apoptosis of cytokineprimed human vascular smooth muscle cells. Arterioscler. Thromb. Vasc. Biol. 17: 2200-2208

44. Sata M, Perlman $H$, Muruve DA, Silver M, Ikebe M, Libermann TA, Oettgen $P$ and Walsh K (1998) Fas ligand gene transfer to the vessel wall inhibits neointima formation and overrides the adenovirus-mediated $T$ cell response. Proc. Natl. Acad. Sci. USA 95: 1213-1217

45. Sata M and Walsh K (2000) Fas ligand-deficient mice display enhanced leukocyte infiltration and intima hyperplasia in flow-restricted vessels. J. Mol. Cell. Cardiol. 32: 1395-1400

46. Libby P, Geng YJ, Sukhova GK, Simon DI and Lee RT (1997) Molecular determinants of atherosclerotic plaque vulnerability. Ann. NY Acad. Sci. 811: 1

47. Mayr $M$ and $X u Q$ (2001) Smooth muscle cell apoptosis in arteriosclerosis. Exp. Gerontol. 36: 969-987

48. Geng YJ, Liao H-S and Macgovern J (1998) Expression of FasL in advanced human atherosclerotic lesions: implications for co-occurrence of immunocytoxicity and immune privilege. Circulation 98 (Suppl I): I-48

49. Boyle JJ, Bowyer DE, Weissberg PL and Bennett MR (2001) Human bloodderived macrophages induce apoptosis in human plaque-derived vascular smooth muscle cells by Fas-ligand/Fas interactions. Atheroscle. Thromb. Vasc. Biol. 21: 1402-1407

50. Shimizu M, Fukuo K, Nagata S, Suhara T, Okuro M, Fujii K, Higashino Y, Mogi M, Hatanaka $Y$ and Ogihara T (2002) Increased plasma levels of the soluble form of Fas ligand in patients with acute myocardial infarction and unstable angina pectoris. J. Am. Coll. Cardiol. 39: 585-590

51. Pinkoski MJ and Green DR (1999) Fas ligand, death gene. Cell Death Differ. 6: 1174-1181

52. Crabtree GR and Clipstone NA (1994) Signal transmission between the plasma membrane and nucleus of T lymphocytes. Annu. Rev. Biochem. 63: 10451083

53. Latinis KM, Norian LA, Eliason SL and Koretzky GA (1997) Two NFAT transcription factor binding sites participate in the regulation of CD95 (Fas) ligand expression in activated human T cells. J. Biol. Chem. 272: 31427-31434

54. Rivera I, Harhaj EW and Sun S-C (1998) Involvement of NF-AT in type I human T-cell leukemia virus Tax-mediated Fas ligand promoter transactivation. J. Biol. Chem. 273: 22382-22388

55. Li XX and Stark GR (2002) NF kappa B-dependent signaling pathways. Exp. Hematol. 30: 285-296

56. Lee Jl and Burckart GJ (1998) Nuclear factor kappa B: important transcription factor and therapeutic target. J. Clin. Pharmacol. 38: 981-993

57. Matsui K, Fine A, Zhu B, Marshak-Rothstein A and Ju ST (1998) Identification of two NF-kappa B sites in mouse CD95 ligand (Fas ligand) promoter: functional analysis in T cell hybridoma. J. Immunol. 161: 3469-3473

58. Kasibhatla S, Brunner T, Genestier L, Echeverri F, Mahboubi A and Green DR (1998) DNA damaging agents induce expression of Fas ligand and subsequent apoptosis in T lymphocytes via the activation of NF- $\kappa$ B and AP-1. Mol. Cell 1 : $543-551$

59. Kasibhatla S, Genestier L and Green DR (1999) Regulation of fas-ligand expression during activation-induced cell death in T lymphocytes via nuclear factor kappaB. J. Biol. Chem. 274: 987-992

60. Kavurma MM, Santiago FS, Bonfoco E and Khachigian LM (2001) Sp1 phosphorylation regulates apoptosis via extracellular FasL-Fas engagement. J. Biol. Chem. 276: 4964-4971

61. Kavurma MM, Bobryshev U and Khachigian LM (2002) Ets-1 positively regulates Fas ligand transcription via co-operative interactions with Sp1. J. Biol. Chem. (in press)

62. Xiao S, Matsui K, Fine A, Zhu B, Marshak-Rothstein A, Widom RL and Ju ST (1999) FasL promoter activation by IL-2 through SP1 and NFAT but not Egr-2 and Egr-3. Eur. J. Immunol. 29: 3456-3465

63. Mittelstadt PR and Ashwell JD (1998) Cyclosporin A-sensitive transcription factor Egr-3 regulates Fas ligand expression. Mol. Cell. Biol. 18: 3744-3751

64. Silverman ES and Collins T (1999) Pathways of Egr-1-mediated gene transcription in vascular biology. Am. J. Pathol. 153: 665-670

65. Li-Webber M, Laur O and Krammer PH (1999) Novel Egr/NF-AT composite sites mediate activation of the CD95 (APO-1/Fas) ligand promoter in response to T cell stimulation. Eur. J. Immunol. 29: 3017-3027 
66. Mittelstadt PR and Ashwell JD (1999) Role of Egr-2 in up-regulation of Fas ligand in normal T cells and aberrant double-negative 1pr and gld T cells. J. Biol. Chem. 274: 3222-3227

67. Rengarajan J, Mittelstadt PR, Mages HW, Gerth AJ, Kroczek RA, Ashwell JD and Glimcher LH (2000) Sequential involvement of NFAT and Egr transcription factors in FasL regulation. Immunity 12: 293-300

68. Yang Y, Dong B, Mittelstadt PR, Xiao H and Ashwell JD (2002) HIV Tat binds Egr proteins and enhances Egr-dependent transactivation of the Fas Ligand promoter. J. Biol. Chem. 277: 19482-19487

69. Chow WA, Fang JJ and Yee JK (2000) The IFN regulatory factor family participates in regulation of Fas ligand gene expression in T cells. J. Immunol. 164: 3512-3518

70. Kirschhoff S, Sebens T, Baumann S, Krueger A, Zawatzky R, Li-Webber M, Meinl E, Neipel F, Fleckenstein B and Krammer PH (2002) Viral IFN-regulatory factors inhibit activation-induced cell death via two positive regulatory IFNregulatory factor 1-dependent domains in the CD95 ligand promoter. J. Immunol. 168: 1226-1234

71. Evan Gl, Wyllie AH, Gilbert CS, Littlewood TD, Land H, Brooks M, Waters CM, Penn LZ and Hancock DC (1992) Induction of apoptosis in fibroblasts by c-myc protein. Cell 69: 119-128

72. Shi Y, Glynn JM, Guilbert LJ, Cotter TG, Bissonnette RP and Green DR (1992) Role for c-myc in activation-induced apoptotic cell death in T cell hybridomas. Science 257: 212-214

73. Bissonnette RP, McGahon A, Mahboubi A and Green DR (1994) Functional Myc-Max heterodimer is required for activation-induced apoptosis in $\mathrm{T}$ cell hybridomas. J. Exp. Med. 180: 2413-2418

74. Hueber AO, Zornig M, Lyon D, Suda T, Nagata S and Evan GI (1997) Requirement for the CD95 receptor-ligand pathway in c-Myc-induced apoptosis. Science 278: 1305-1309

75. Brunner T, Kasibhatla S, Pinkoski MJ, Frutschi C, Yoo NJ, Echeverri F, Mahboubi A and Green DR (2000) Expression of Fas ligand in activated T cells is regulated by c-Myc. J. Biol. Chem. 275: $9767-9772$

76. Kasibhatla S, Beere HM, Brunner T, Echeverri F and Green DR (2000) A 'noncanonical' DNA-binding element mediates the response of the Fas-Ligand promoter to c-Myc. Curr. Biol. 10: 1205-1208

77. Genestier L, Kasibhatla S, Brunner T and Green DR (1999) Transforming growth factor $\beta 1$ inhibits Fas ligand expression and subsequent activationinduced cell death in T cells via downregulation of c-Myc. J. Exp. Med. 189: 231-239

78. Brunet A, Bonni A, Zigmond MJ, Lin MZ, Juo P, Hu LS, Anderson MJ, Arden KC, Blenis J and Greenberg ME (1999) Akt promotes cell survival by phosphorylating and inhibiting a Forkhead transcription factor. Cell 96: 857868

79. Suhara T, Kim H-S, Kirshenbaum LA and Walsh K (2002) Suppression of Akt signaling induces Fas Ligand expression: involvement of caspase and Jun kinase activation in Akt-mediated FasL regulation. Mol. Cell. Biol. 22: 680-691

80. Faris M, Latinis KM, Kempiak SJ, Koretzky GA and Nel A (1998) Stressinduced Fas ligand expression in T cells is mediated through a MEK kinase 1. regulated response element in the Fas ligand promoter. Mol. Cell. Biol. 18: 5414-5424

81. Le-Niculescu H, Bonfoco E, Kasuya Y, Claret F-X, Green DR and Karin M (1999) Withdrawal of survival factors results in activation of the JNK pathway in neuronal cells leading to Fas ligand induction and cell death. Mol. Cell. Biol. 19: 751-763

82. Akbar AN, Borthwick NJ, Wickremasinghe RG, Panayoitidis P, Pilling D, Bofill M, Krajewski S, Reed JC and Salmon D (1996) Interleukin-2 receptor common gamma-chain signaling cytokines regulate activated $\mathrm{T}$ cell apoptosis in response to growth factor withdrawal: selective induction of anti-apoptotic (bcl2 , bcl-xL) but not pro-apoptotic (bax, bcl-xS) gene expression. Eur. J. Immunol. 26: 294-299

83. Radvanyi LG, Raju K, Spaner D, Mills GB and Miller RG (1998) Interleukin-2 reverses the defect in activation-induced apoptosis in $\mathrm{T}$ cells from autoimmune $1 \mathrm{pr}$ mice. Cell. Immunol. 183: 1-12

84. Horak I, Lohler J, Ma A and Smith KA (1995) Interleukin-2 deficient mice: a new model to study autoimmunity and self-tolerance. Immunol. Rev. 148: 35-44

85. Haux J, Johnsen AC, Steinkjer B, Egeberg K, Sundan A and Espevik T (1999) The role of interleukin- 2 in regulating the sensitivity of natural killer cells for Fasmediated apoptosis. Cancer Immunol. Immunother. 48: 139-146

86. Refaeli Y, Vanparijs L, London CA, Tschopp J and Abbas AK (1998) Biochemical mechanisms of IL-2-regulated Fas-mediated T cell apoptosis. Immunity 8: 615-623

87. Ayroldi E, Zollo O, Cannarile L, D'Adamio F, Grohmann U, Delfino DV and Riccardi C (1998) Interleukin-6 (IL-6) prevents activation-induced cell death: IL2-independent inhibition of Fas/FasL expression and cell death. Blood 92: 4212-4219

88. Teague TK, Marrack P, Kappler JW and Vella AT (1997) IL-6 rescues resting mouse T cells from apoptosis. J. Immunol. 158: 5791-5796

89. Massague J (1990) The transforming growth factor-beta family. Annu. Rev. Cell Dev. Biol. 6: 597-641

90. Cerwenka A, Kovar H, Majdic O and Holter W (1996) Fas- and activationinduced apoptosis are reduced in human $T$ cells preactivated in the presence of TGF-beta 1. J. Immunol. 156: 459-464

91. Schlapbach R, Spanaus K-S, Malipiero U, Lens S, Tasinato A, Tschopp J and Fontana A (2000) TGF- $\beta$ induces the expression of the FLICE-inhibitory protein and inhibits Fas-mediated apoptosis of microglia. Eur. J. Immunol. 30: 36803688

92. Dünker N, Schmitta K and Krieglsteina K (2002) TGF- $\beta$ is required for programmed cell death in interdigital webs of the developing mouse limb. Mech. Dev. 113: 111-120

93. Arsura M, Wu M and Sonenshein GE (1996) TGF $\beta 1$ inhibits NF- $\kappa$ B/Rel activity inducing apoptosis of $B$ cells: transcriptional activation of $\mid \kappa B$. Immunity $5: 31-$ 40

94. Yang Y, Mercep M, Ware CF and Ashwell JD (1995) Fas and activationinduced Fas ligand mediate apoptosis of $T$ cell hybridomas: inhibition of Fas ligand expression by retinoic acid and glucocorticoids. J. Exp. Med. 181: 16731682

95. Lee MO, Kang HJ, Kim YM, Oum JH and Park J (2002) Repression of FasL expression by retinoic acid involves a novel mechanism of inhibition of transactivation function of the nuclear factors of activated T-cells. Eur. J. Biochem. 269: 1162-1170

96. Yang Y, Minucci S, Ozato K, Heyman RA and Ashwell JD (1995) Efficient inhibition of activation-induced Fas ligand up-regulation and $T$ cell apoptosis by retinoids requires occupancy of both retinoid $X$ receptors and retinoic acid receptors. J. Biol. Chem. 270: 18672-18677

97. Melino G, Bernassola F, Catani MV, Rossi A, Corazzari M, Sabatini S, Vilbois F and Green DR (2000) Nitric oxide inhibits apoptosis via AP-1-dependent CD95L transactivation. Cancer Res. 60: 2377-2383

98. Cippitelli M, Fionda C, Di Bona D, Di Rosa F, Lupo A, Piccoli M and Fra Santoni A (2002) Negative regulation of CD95 ligand gene expression by vitamin D3 in T lymphocytes. J. Immunol. 168: 1154-1166

99. Bodor J, Bodorova J, Bare C, Hodge DL, Young HA and Gress RE (2002) Differential inducibility of the transcriptional repressor ICER and its role in modulation of Fas ligand expression in T and NK lymphocytes. Eur. J. Immunol. 32: 203-212 